\title{
Clinical Profile of Children with Cerebral Palsy
}

\section{Pooja Kumari ${ }^{1}$, Jayant Vagha², Prachi Palsodkar ${ }^{3}$}

\section{IJCRR}

Section: Healthcare

Sci. Journal Impact

Factor: $6.1(2018)$

ICV: 90.90 (2018)
Junior Resident, Department of Pediatrics, Jawaharlal Nehru Medical College, Datta Meghe Institute of Medical Sciences, Sawangi, Wardha, India; 'Professor, Department of Pediatrics, Jawaharlal Nehru Medical College, Datta Meghe Institute of Medical Sciences, Sawangi, Wardha, India; ${ }^{3}$ Professor, Electronics Engineering, Yeshwantrao Chavan College of Engineering, Nagpur, India.

\section{ABSTRACT}

Background: Cerebral palsy is a broad range of static, non-progressive motor disabilities that present from birth or early childhood as a result of injury to neuromotor components of the central nervous system. Etiologies are numerous and can occur during prenatal perinatal and postnatal periods.

Methods: The study was conducted throughout 1year in the department of Paediatrics JNMC, Sawangi. The study population included children diagnosed with CP. Exclusion criteria were non-consenting patients with non-central causes of motor deficit. The cases were studied for presentation and sent for appropriate referrals during study and analysis was done by the use of appropriate statistical methods. The patient is diagnosed with help of history and clinical finding which are correlated together to make a diagnosis of cerebral palsy. Special focus is given on the central nervous system examination. Total of 113 patients is included in the study up to the age of 16 years.

Expected Results: During the study period 113 patients up to the age of 16 years are expected to show functional disability and developmental delay with an overall male: female ratio of 1.3:1 and more commonly in male patients.

Key Words: Clinical profile, Cerebral palsy, Developmental delay, Children, Perinatal insult

\section{INTRODUCTION}

The paediatric population has many children with developmental delay. Cerebral palsy (CP) is the commonest cause for developmental delay. Cerebral palsy is the commonest chronic disability of childhood today. It is ubiquitous, and it occurs all across the globe. It occurs from injury to the brain cells, motor defects that may be progressive and affect for their whole life. Cerebral dysfunction is also associated with movement and disorders in posture or balance. Disturbed mechanisms for balance, the abnormal tone for muscle, muscle weakness, and loss of selective motor control lead to an inability to stretch muscles and its proper functioning, and it leads to contractures and deformities in patients which affect the daily lifestyle of parents and makes patient dependable on others. Treatment should start at a very early age or at the time of diagnosis when they are infants and continued into adulthood. Without proper treatment, these children cannot become productive members of society. ${ }^{1} \mathrm{CP}$ is a group of permanent disorders of movement and posture causing ac- tivity limitation, that is attributed to non-progressive disturbances in the developing brain. ${ }^{2}$

It is known as "an umbrella term covering a group of nonprogressive, but often changing, motor impairment syndromes secondary to lesions or anomalies of the brain arising in the early stages of its development. ${ }^{2}$ When primary lesion, injury or trauma is static, the clinical pattern change with due course of time due to growth and developmental and maturation of the central nervous system ${ }^{3}$ and may be called as static encephalopathy. Chief clinical feature of $\mathrm{CP}$ is primarily motor dysfunction, sensory, cognitive, and verbal impairment in addition to learning difficulties and behavioural problems are common. ${ }^{4}$

By topographical classification of Cerebral Palsy is of 4 types that is Monoplegic CP, Hemiplegic CP, Diplegic CP and Quadriplegic CP; Uncommon form is monoplegia and triplegia. In different studies, diplegia is being the commonest form ranging from $(30 \%-40 \%)$ and is followed by hemiplegia which is $20 \%-30 \%$, and quadriplegia which accounts

\section{Corresponding Author:}

Pooja Kumari, Department of Pediatrics, Jawaharlal Nehru Medical College, Datta Meghe Institute of Medical Sciences, Sawangi, Wardha, India; Contact: 8340177165; Email: pooja12690@gmail.com

ISSN: 2231-2196 (Print)

Received: 22.08 .2020
ISSN: $0975-5241$ (Online)

Revised: 18.09 .2020
Accepted: 27.10 .2020 
for $10 \%-15 \%$. In a study of 1000 cases of CP from India, it was revealed that spastic quadriplegia constituted $61 \%$ of cases followed by diplegia $22 \%{ }^{5}$

Cerebral palsy is a common problem and its incidence in worldwide being 2.7 per one thousand live births. ${ }^{6}$ When Little described Cerebral palsy, and cause for it to birth trauma and this view has remained consistent for many years. A decrease in its prevalence is important to sign of success in the prevention of CP. "contrary to initial expectations with improvements in perinatal medicine including the use of fetal monitoring and cesarean section the prevalence of cerebral palsy has not decreased ${ }^{7}$ was stated in a populationbased study conducted in united states. Epidemiology of CP concerning weight and age- Term birth babies are comparatively less prone to cerebral palsy but most infants are term born. On the other hand, the risk of CP in preterm births is relatively high. ${ }^{8}$ There are various risk factors example low birth weight, birth asphyxia or seizure disorder, malnutrition, premature baby but several studies have assessed the relationship between chorioamnionitis and cerebral palsy in prematureinfants ${ }^{9}$, but most have not reported a significant association. ${ }^{9}$ But this study indicates that chorioamnionitis is a risk factor for cerebral palsy. ${ }^{10}$

The demography, causes, clinical features and management aspects are planned to study in this project to prevent complications and provide better life quality.

\section{METHODS}

Type of study: Prospective observational study

Setting: The present study will be conducted at the Department of Pediatrics AVBRH, JNMC Sawangi, Wardha. It will be conducted for three years, with a sample size of 113 .

The study will be initiated only after obtaining permission from the Institutional Ethics Committee, AVBRH, JNMC Sawangi, Wardha.

Statistical criteria: Population proportion $=0.3$

Sample proportion $=0.2$

Power $=90 \%$

Alpha error $=5 \%$

Sided $=2$

Sample size $=113$

\section{Participants:}

\section{Inclusion criteria}

1) All patients with the diagnosis of cerebral palsy referred to the Department of Pediatrics either IPD or OPD.
2) Age Group for the study: children till 16 years

3) Both gender.

\section{Exclusion criteria}

1) Unwillingness to participate in the study.

2) Non-central causes of motor deficits

3) Age more than 16 years

The patient attending OPD will be screened for the eligibility criteria. The participants meeting the set criteria would be explained about the nature and purpose of the study. Written and informed consent will be taken from those willing to participate in the study. The would-be ensured confidentiality.

\section{Methodology}

After taking clearance from the ethical committee, the patient will be selected according to the inclusion and exclusion criteria. Informed written consent will be taken from every patient who agrees to follow instruction and recommendation given by the clinician. Patient biography, detail history and clinical examination will be done. The study will be conducted throughout 1year in the department of Paediatrics Jawaharlal Nehru Medical College, Sawangi. The study population included children diagnosed with CP. Exclusion criteria were non-consenting patients with non-central causes of motor deficit. The cases were studied for presentation and sent for appropriate referrals during study and analysis was done by the use of appropriate statistical methods. The study was conducted over 1 year in the department of paediatrics JNMC, Sawangi. Ethical committee approval was obtained before the start of the study. The study population included was children diagnosed with cerebral palsy below the age of 16 years who were admitted in the pediatric department. The exclusion criteria were non-consenting patients and cases with non-central causes of motor deficit. Their history, examination and investigations were done according to the pieces of advice of the treating physician. During hospitalization, the cases were studied for presentation, causes, course, comorbidities and outcome. Children were sent for appropriate referrals during hospitalization. All the information was recorded in pre-validated proforma. The results were interpreted by the use of appropriate statistical methods.

Variables: Motor function, loss of developmental delay

Bias: Child less than 1 year of age is difficult to diagnose clinically hence it is a bias in the study as we have no lower limit of age.

Study size: 113 patients

Quantitative variables: Age, height, weight, Head circumference, BMI

Statistical analysis: All the obtained results will be evaluated using SPSS 6. 
Expected Outcomes/Results: Results will be summarised as below- Number of cases included for analysis. Sex Distribution of study participants, sex ratio, prevalence among males and females, the age distribution of participants, topographical type of cerebral palsy, association with different clinical features, socioeconomic status as well as anthropometric measures.

\section{DISCUSSION}

As per the study CP is more common in males. ${ }^{11}$ Age distribution was for more than 5 years and less than 2 years (24\%) and between 2-5 years (52\%). The motor deficits in the form of difficulty in walking and the use of hands for appropriate tasks were the most common disability as the study had cases mostly with diplegic and quadriplegic $\mathrm{CP}$. The most common comorbidities were pneumonia and gastroenteritis. Majority of the children were malnourished grade I (56\%), grade II (30\%), grade III (4\%). $10 \%$ of patients have a behavioural problem. Subnormal intelligence, convulsions, malnutrition, hearing impairment, visual problems, speech and language delay, gastrointestinal problem, a dental problem, respiratory problem, orthopaedic problem, sleep disorder were commonest associated comorbidities in the cases. Several articles on different aspects of child health from this region were reviewed. ${ }^{12-13} \mathrm{~A}$ rare presentation of isolated oculomotor nerve palsy due to multiple sclerosis in a child as well as infant. ${ }^{14-19}$ Also, studies on the effects of electronic media ${ }^{20}$ and care-seeking behaviour of children's families ${ }^{21}$ were reported. Studies from the Global Burden of Disease are also available which will help to draw the conclusion and make recommendation based on the observations..$^{22,23}$

\section{ACKNOWLEDGMENT}

Authors acknowledge the immense help received from the scholars whose articles are cited and included in references to this manuscript. The authors are also grateful to authors / editors / publishers of all those articles, journals, and books from which the literature for this article has been reviewed and discussed.

\section{Conflict of Interest: Nil}

Source of Funding: Nil

\section{REFERENCES}

1. Berker AN, Yalçın MS. Cerebral palsy: orthopaedic aspects and rehabilitation. Pediatr Clin North Am 2008;55(5):1209-25.

2. Mutch L, Alberman E, Hagberg B, Kodama K, Perat MV. Cerebral palsy epidemiology: where are we now and where are we going? Dev Med Child Neurol 1992;34(6):547-51.
3. Sankar C, Mundkur N. Cerebral palsy-definition, classification, etiology and early diagnosis. Indian J Pediatr 2005;72(10):8658.

4. Kilincaslan A, Mukaddes NM. Pervasive developmental disorders in individuals with cerebral palsy. Dev Med Child Neurol 2009;51(4):289-94.

5. Singhi PD, Ray M, Suri G. Clinical spectrum of cerebral palsy in North India - an analysis of 1000 cases. J Tropic Paediatr 2002;48(3):162-6.

6. Rosen MG, Dickinson JC. The incidence of cerebral palsy. Am J Obstetr Gynaecol 1992;167(2):417-23.

7. Winter S, Autry A, Boyle C, Yeargin-Allsopp M. Trends in the prevalence of cerebral palsy in a population-based study. Paediatrics 2002;110(6):1220-5.

8. Hagberg B, Hagberg G, Zetterström R. Decreasing perinatal mortality-increase in cerebral palsy morbidity? Acta Paediatrica 1989;78(5):664-70.

9. Yoon BH, Jun JK, Romero R, Park KH, Gomez R, Choi JH, et al. Amniotic fluid inflammatory cytokines (interleukin-6, interleukin- $1 \beta$, and tumour necrosis factor- $\alpha$ ), neonatal brain white matter lesions, and cerebral palsy. Am J Obstetr Gynaecol 1997;177(1):19-26.

10. Wu YW, Colford Jr JM. Chorioamnionitis as a risk factor for cerebral palsy: a meta-analysis. JAMA 2000;284(11):1417-24.

11. Mallick S. Study On The Clinical Profile Of Patients With Cerebral Palsy (Doctoral dissertation).

12. Garg S, Chakravarti A, Singh R, Masthi NR, Goyal RC, Jammy GR, et al. Dengue serotype-specific seroprevalence among 5-to 10-year-old children in India: a community-based cross-sectional study. Int J Infect Dis 2017;54:25-30.

13. Puri S, Fernandez S, Puranik A, Anand D, Gaidhane A, Syed ZQ, et al. Policy content and stakeholder network analysis for infant and young child feeding in India. BMC Public Health 2017;17(2):461.

14. Taksande A, Meshram R, Lohakare A. A Rare Presentation of Isolated Oculomotor Nerve Palsy due to Multiple Sclerosis in a Child. Int J Pediatr 2017;5(8):5525-9.

15. Taksande A, Meshram R, Yadav P, Borkar S, Lohakare A, Banode P. A Rare Case of Budd Chiari Syndrome in a Child. Int J Pediatr 2017;5(10):5809-12.

16. Taksande A, Meshram R, Yadav P, Lohakare A. Rare presentation of cerebral venous sinus thrombosis in a child. J Pediatr Neurosci 2017;12(4):389.

17. Mishra KK, Kelkar P, Kumar K. An interesting case of trichotillomania in a pre-school child. J Indian Asso Child Adolesc Mental Health 2018;14(4).

18. Thow AM, Karn S, Devkota MD, Rasheed S, Roy SK, Suleman $\mathrm{Y}$, et al. Opportunities for strengthening infant and young child feeding policies in South Asia: Insights from the SAIFRN policy analysis project. BMC Public Health 2017;17(2):404.

19. Uddin S, Mahmood H, Senarath U, Zahiruddin Q, Karn S, Rasheed S, et al. Analysis of stakeholders networks of infant and young child nutrition programmes in Sri Lanka, India, Nepal, Bangladesh and Pakistan. BMC Public Health 2017;17(2):405.

20. Khatib MN, Sinha A, Gaidhane AM, Simkhada P, Behere PB, Saxena D, et al. A systematic review of the effect of electronic media among children and adolescents on substance abuse. Indian J Comm Med 2018;43(1): S66.

21. Mittal V, Jagzape T, Sachdeva P. Care Seeking Behaviour of Families for their Sick Infants and Factors Impeding to their 
Early Care Seeking in Rural Part of Central India. J Clin Diagnos Res 2018;12(4).

22. James SL, Castle CD, Dingels ZV, Fox JT, Hamilton EB, Liu Z, et al. Estimating global injuries morbidity and mortality: methods and data used in the Global Burden of Disease 2017 study. Injury Prevention 2020;26(1):i125-53.
23. James SL, Castle CD, Dingels ZV, Fox JT, Hamilton EB, Liu Z, Roberts NL, Sylte DO, Henry NJ, LeGrand KE, Abdelalim A. Global injury morbidity and mortality from 1990 to 2017 : results from the Global Burden of Disease Study 2017. Injury Prevention 2020 Apr 20. DoI: https://doi.org/10.1136/injuryprev-2019-043494. 